\title{
Impact of a dual task intervention on physical performance of older adults who practice physical exercise
}

\section{Impacto de uma intervenção de dupla tarefa no desempenho físico de idosos praticantes de exercício físico}

\author{
Larissa Borges Medeiros ${ }^{1}$ \\ Juliana Hotta Ansai ${ }^{2}$ \\ Marcele Stephanie de Souza Buto ${ }^{1}$ \\ Verena de Vassimon Barroso ${ }^{1}$ \\ Ana Claudia Silva Farche ${ }^{1}$ \\ Paulo Giusti Rossi ${ }^{1}$ \\ Larissa Pires de Andrade ${ }^{1}$ \\ Anielle Cristhine de Medeiros Takahashi ${ }^{1}$
}

Abstract - Physical exercises, especially multicomponent training, can improve cognitive functions and physical impairments in older adults. The aim this study was to purpose of this two-arm clinical trial was to investigate the effects of the addition of a dual task to multicomponent training on physical performances of community-dwelling older adults who practice physical exercise. Seventy-one older adults were divided into a Control Group (CG) and Intervention Group (IG). Participants of the CG performed isolated multicomponent training, participants of the IG performed multicomponent training associated with cognitive tasks and both protocols lasted 12 weeks. The assessment consisted of flexibility, handgrip strength, lower limb strength, balance, functional mobility and aerobic capacity. The CG presented greater flexibility than the IG, regardless of time. There was a worse performance in lower limb strength, regardless of group. The addition of a dual task to the multicomponent training was not able to improve physical performances of older adults. Further studies are needed to confirm whether the dual task training contributes to both cognitive and physical benefits in older adults who practice physical exercise.

Key words: Aged; Clinical trial; Exercise.

Resumo - Exercícios físicos, especialmente o treinamento multicomponente, podem melhorar funçôes cognitivas e distúrbios motores em idosos. Objetivou-se investigar os efeitos da adição da dupla tarefa sobre o treinamento multicomponente nas performances motoras de idosos da comunidade praticantes de exercício físico. Setenta e um idosos foram divididos em Grupo Controle (GC) e Grupo Intervenção (GI). Participantes do GCrealizaram treinamento multicomponente isolado e participantes do GI realizaram treinamento multicomponente associado a tarefas cognitivas, ambos protocolos com duração de 12 semanas. A avaliação consistiu de flexibilidade, força de preensão palmar, força de membros inferiores, equilíbrio, mobilidade funcional e capacidade aeróbica. O GC apresentou maior flexibilidade do que o GI, independente do tempo. Houve uma piora na performance de força de membros inferiores, independente do grupo. A adição da dupla tarefa sobre o treinamento multicomponente não foi capaz de melhorar performances físicas de idosos. Estudos futuros são necessários para confirmar se o treinamento de dupla tarefa traz benefícios cognitivos e também físicos em idosos praticantes de exercício físico.

Palavras-chave: Ensaio clinico; Exercício; Idoso.
1 Federal University of São Carlos. Department of Physical Therapy. São Carlos, SP. Brazil.

2 Federal University of Mato Grosso do Sul. Department of Physical Therapy. Campo Grande, MS. Brazil.

Received: March 14, 2017 Accepted: January 17, 2018

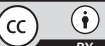




\section{INTRODUCTION}

Physical impairments among older people can be minimized through regular and systematic practice of physical exercise, especially multicomponent training (a combination of strength, endurance, flexibility, motor coordination, and balance exercises $)^{1-2}$. Furthermore, physical exercises can improve cognitive functions ${ }^{3}$ and delay the onset of dementia ${ }^{4}$.

Dual task (physical exercise combined with another task) protocols can be effective in improving cognitive function in older adults with and without cognitive impairment ${ }^{5}$. Although some studies have contributed to understanding the effects of dual task training in older adults, previous works included older people with cognitive impairment ${ }^{6}$, Parkinson's disease $^{7}$, or a sedentary lifestyle ${ }^{8}$. In healthy older adults who practice physical exercise, it was observed an improvement in gait performance after the dual task training.

Older adults perform daily activities that interplays cognitive and motor functions. Thus, the combination of motor and cognitive stimulus seems to be important to maintain an independent life ${ }^{10}$, even in health older people. Besides, most studies involving dual task training restricted the outcomes to cognitive performance and not to physical performance ${ }^{5}$, which can be used as primary indicators of benefits in future clinical trials ${ }^{11}$.

Community-dwelling older adults who practice physical exercise present a high level of physical performance ${ }^{12}$, however it remains unknown the effects of dual task training on this domain, mainly on other physical parameters besides gait. Thus, the aim of this study was to investigate the effects of the addition of a dual task to a multicomponent training protocol on physical performances (flexibility, muscular strength, balance, functional mobility, and aerobic capacity) among community-dwelling older adults who practice physical exercise. The hypothesis of the present study was that the dual task training would present a greater benefit in physical performance variables compared to the multicomponent training.

\section{METHODOLOGICAL PROCEDURES}

\section{Sample}

The two-arm clinical trial was registered (Clinical Trials Registration ID: NCT02235922) and approved by the Ethics Committee of the Federal University of São Carlos (ID: 436.821/2013). All volunteers signed the written consent form.

Inclusion criteria were community-dwelling adults aged 60 years and over, who had practiced at least one year of regular supervised physical exercise (Revitalization Program) and had the ability to walk alone without an aid. The Revitalization Program aims to improve quality of life in older adults through a multicomponent training protocol based on recommendations of the ACSM (2009)2. Exclusion criteria were the presence of Parkinson's disease, dementia or cerebrovascular accident, assessed by a self-reported 
questionnaire, and an attendance rate below $70 \%$ in the Revitalization Geriatric Program, according to its rules. Assuming the type of study design, a type I error of 5\%, statistical power of $80 \%$, and effect size of 0.35 , a minimum of 66 participants were required to constitute the total sample.

According to the organization of the Revitalization Geriatric Program, individuals were initially divided into 6 classes. The randomization of the groups was done using a raffle with closed papers numbered sequentially, which allocated three classes to the intervention group (IG) and three other classes to the control group (CG).

Recruitment was conducted between 2013 and 2014. Initially, there were 78 eligible older adults. Of these, seven people were excluded because of an attendance rate in the activities below $70 \%$.

\section{Assessment}

The assessments were performed by six trained physiotherapists. The baseline assessment included an anamnesis composed of anthropometric data, the Modified Baecke Questionnaire for the elderly (MBQE) ${ }^{13}$, and history of falls in the previous four month ${ }^{14}$ Tinetti Mobility Score (TMS).

All functional performance tools were chosen because they are commonly used screening tools and easy to apply, and they use accessible and low cost materials. Furthermore, the Revitalization Geriatric Program have applied them since 2007 and the Program's participants have not had difficult to comprehend and perform these tools. The Wells bench was used to assess trunk flexibility. The test was performed three times and the maximum value (in centimetres) was analysed ${ }^{15}$. Handgrip strength was measured by the JAMAR adjustable hand dynamometer (Sammons Preston, Warrenville, United States). Three measures of the dominant member were collected and the maximum value was analysed. The cut-off score was adjusted for sex and body mass index $(\mathrm{BMI})^{16}$. Lower limb strength was assessed by 30 -second chair stand test (30-s CST) and 5 times sitto-stand test (5XSST). A pre-test and one trial were performed. The 30-s CST score is based on the number of stands within 30 seconds and the cut-off score depends on sex and age ${ }^{17}$. The 5 XSST score is based on the time taken and a time of 11.19 seconds is considered a good performance ${ }^{18}$.

Functional mobility was measured by the Timed Up and Go test (TUG) at habitual speed. A cut-off score of 12.47 seconds is predictive of a risk of falls in Brazilian older adults ${ }^{19}$. The one-leg stance test was used to assess balance. The older adult had three chances for each member and tried to remain in this position for 30 seconds. A time less than 5 seconds is indicative of a risk of falls and for this test the highest time for each member was analysed ${ }^{20}$. The 6-minute walk test (6MWT) along a 30 -meter corridor was performed to assess aerobic capacity. The cut-off score (meters) depends on age and sex ${ }^{17}$.

\section{Intervention}

Participants of the CG performed isolated multicomponent training and 
participants of the IG performed multicomponent training associated with cognitive tasks. Both protocols lasted 12 weeks and included three 50-minute sessions per week, on non-consecutive days. The protocols were supervised by physiotherapists and physical education professionals.

Both multicomponent training protocols followed recommendations of the ACSM for older adults ${ }^{2}$. The multicomponent training protocol included aerobic, flexibility, muscular strength, and balance exercises, with progressive intensity (assessed by the Borg scale and a heart rate monitor). The sessions were distributed as follows: 10 minutes of warm-up (walking, with increased velocity); 30 minutes of muscle strength, balance and coordination exercises (muscle strength of lower and upper limbs using halters, weights or elastic band, sit to stand from the chair, step up and down, lunges, circuits of static and dynamic balance, walk in tandem or in circles); and 10 minutes of flexibility (global stretching exercises). Both groups received the same physical stimulus during the sessions.

The participants performed motor tasks associated with cognitive tasks, with progressive complexity ${ }^{6}$. The protocol was divided into four stages. In the first stage (between the first and third weeks), the participants were stimulated to perform less complex cognitive tasks, such as counting down in ones (e.g., 20, 19, 18...), twos (e.g., 20, 18, 16...), fives (e.g., 20, $15,10 \ldots)$ and so on. In the second stage (between the fourth and sixth weeks), cognitive tasks involved evoking names of cities, flowers, fruits, and animals. The complexity was increased when the words started with a specific letter of the alphabet. The third stage (seventh to ninth weeks) consisted of mathematical operations, such as addition, subtraction, and multiplication. The final stage was performed using cards with different colours and actions described (e.g., blue card associated with jumping). The volunteers were asked to read the action described on the card, then say the action based only on the colour, read and perform the action described on the card and finally perform the action based only on observation of the colour. Further explanations can be found in Ansai et al. ${ }^{21}$.

\section{Data analysis}

Statistical analyses were performed using SPSS software (version 20.0) (Chicago, Illinois, USA), with a significance level of 5\%. The normality of all data was tested by the Kolmogorov-Smirnov test and all of them presented a normal distribution. The Independent Student $t$ test for quantitative variables and the Chi-square test for categorical variables were applied to compare clinical and demographic data between groups. Multivariate analysis of variance (MANOVA) was used to verify interaction between groups and times, with flexibility, handgrip strength, lower limb strength, balance, mobility, and aerobic capacity as dependent variables. In addition, descriptive analysis was carried out to verify changes according to the following cutoff scores: handgrip strength ${ }^{16}, 5 \mathrm{XSST}^{18}, 30$-s $\mathrm{CST}^{17}$, one-leg stance $^{20}$, TUG test ${ }^{19}$, and $6 \mathrm{MWT}^{17}$. 


\section{RESULTS}

The IG and CG were composed of 35 and 36 older adults, respectively. There were no significant differences between groups relating to clinical or sociodemographic characteristics. The sample had a predominance of females (77.5\%) and non-fallers (94.4\%), mean age of 68 years, mean BMI of $27.9 \mathrm{~kg} / \mathrm{m}^{2}$, and mean MBQE score of 6.2 points (Table 1). The frequency rate in the sessions was approximately $87.3 \%$ for the IG and $85.8 \%$ for the CG. No adverse events were reported.

Table 1. Clinical and sociodemographic data.

\begin{tabular}{lcccc}
\hline Characteristics & Intervention $(\mathrm{n}=35)$ & Control $(\mathrm{n}=36)$ & Total $(\mathrm{n}=71)$ & P value \\
\hline Age (years) & $67.8 \pm 8.6$ & $68.1 \pm 6.4$ & $68 \pm 7.5$ & 0.901 \\
Female sex, $\mathrm{n}(\%)$ & $28(80)$ & $27(75)$ & $55(77.5)$ & 0.614 \\
BMI $\left(\mathrm{kg} / \mathrm{m}^{2}\right)$ & $28.2 \pm 5.3$ & $27.6 \pm 4.8$ & $27.9 \pm 5.0$ & 0.675 \\
MBQE (score) & $6.2 \pm 2.7$ & $6.2 \pm 2.2$ & $6.2 \pm 2.4$ & 0.990 \\
Non-fallers, $\mathrm{n}(\%)$ & $34(97.1)$ & $33(91.7)$ & $67(94.4)$ & 0.317 \\
\hline
\end{tabular}

Mean \pm Standard Deviation, $\mathrm{n}(\%)=$ number of people (percentage), BMI=Body Mass Index, $\mathrm{MBQE}=$ Modified Baecke Questionnaire for the elderly, $\mathrm{kg} / \mathrm{m}^{2}=\mathrm{kilograms}$ per meter squared.

As shown in Table 2, the MANOVA test demonstrated no significant interactions between groups and times regarding flexibility, handgrip strength, lower limb strength, balance or aerobic capacity variables. There was a significant main effect of group in flexibility $(\mathrm{p}=0.002)$. Regardless of time, the CG demonstrated greater flexibility compared to the IG. A significant main effect of time was found in 5 XSST ( $p=0.000)$ and 30-s CST $(\mathrm{p}=.007)$ performances. Regardless of group, higher time was spent on the $5 \mathrm{XSST}$ (pre-post performance $=-1.7$ seconds) and a lower number of times was achieved during the $30-\mathrm{s}$ CST (pre-post performance $=0.56$ times). Other variables showed no significant main effects of group or time (Table 2).

There was a significant interaction between groups and times only for the time spent in the TUG test $(\mathrm{F}=7.500 ; \mathrm{p}=0.008)$. The IG presented worse performance after 12 weeks, i.e., a difference of 0.71 seconds between times $(p=0.000)$. No significant difference was found between times in the CG $(p=0.473)$ or between groups for any time (Table 2).

Table 2. Physical performances between groups and assessments.

\begin{tabular}{|c|c|c|c|c|c|c|c|c|}
\hline & \multicolumn{2}{|c|}{ Intervention $(n=35)$} & \multicolumn{2}{|c|}{ Control $(n=36)$} & \multirow{3}{*}{$\mathrm{F}$} & \multirow{3}{*}{$\begin{array}{c}\text { P value } \\
\text { Group* } \\
\text { Ass }\end{array}$} & \multirow{3}{*}{$\begin{array}{l}\text { P value } \\
\text { Group }\end{array}$} & \multirow{3}{*}{$\begin{array}{c}P \\
\text { value } \\
\text { Ass }\end{array}$} \\
\hline & Pre & Post & Pre & Post & & & & \\
\hline Characteristics & & & & & & & & \\
\hline Flexibility (cm) & $211.76 \pm 81.68$ & $220.82 \pm 75.38$ & $278.08 \pm 82.35$ & $275.44 \pm 80.13$ & 2.52 & 0.117 & 0.002 & 0.387 \\
\hline Handrip strength (KgF) & $23.36 \pm 8.31$ & $26.14 \pm 8.69$ & $27.36 \pm 6.11$ & $27.00 \pm 5.92$ & 2.78 & 0.100 & 0.411 & 0.542 \\
\hline $5 \mathrm{XSST}(\mathrm{s})$ & $11.29 \pm 2.43$ & $13.14 \pm 3.37$ & $11.34 \pm 2.37$ & $12.90 \pm 2.52$ & 0.20 & 0.655 & 0.865 & 0.000 \\
\hline 30-s CST (times) & $12.76 \pm 3.89$ & $12.44 \pm 3.51$ & $13.22 \pm 3.36$ & $12.05 \pm 2.55$ & 2.44 & 0.123 & 0.962 & 0.007 \\
\hline Right one-leg stance test (s) & $29.95 \pm 7.69$ & $26.91 \pm 6.97$ & $27.38 \pm 6.71$ & $27.06 \pm 7.46$ & 0.08 & 0.776 & 0.862 & 0.716 \\
\hline Left one-leg stance test (s) & $26.93 \pm 7.30$ & $26.51 \pm 7.60$ & $27.28 \pm 7.32$ & $26.99 \pm 6.34$ & 0.01 & 0.899 & 0.797 & 0.490 \\
\hline TUG test $(\mathrm{s})$ & $8.09 \pm 1.25^{\#}$ & $8.81 \pm 1.44^{\#}$ & $8.41 \pm 1.24$ & $8.52 \pm 1.21$ & 7.50 & 0.008 & 0.948 & 0.000 \\
\hline TUG test (steps) & $11.35 \pm 1.61$ & $11.88 \pm 2.05$ & $11.72 \pm 1.79$ & $11.63 \pm 1.97$ & 1.88 & 0.175 & 0.871 & 0.321 \\
\hline 6MWT (m) & $500.2 \pm 84.4$ & $494.1 \pm 78.7$ & $497.2 \pm 66.9$ & $482.2 \pm 63.9$ & 0.45 & 0.504 & 0.702 & 0.118 \\
\hline
\end{tabular}

Ass=Assessment, TUG=Timed Up and go, cm=centimeters, $\mathrm{s}=$ seconds, $\mathrm{KgF}=$ kilogram-force, $5 \mathrm{XSST}=5$ times sit-to-stand, 30-s CST=30second chair stand test, 6MWT=6-minute walk test, $\# p=0.000$. 
Table 3 illustrates physical performances according to the established cutoff scores between times in each group. No relevant differences in handgrip strength or aerobic capacity performances were found between times in any group. However, there was a decrease in the number of volunteers who performed the $5 \mathrm{XSST}$ above the cutoff score in both groups. A worse performance in the 30-s CST was observed only in the CG. Both groups presented TUG and one-leg stance performances above the cutoff scores at baseline, and the good performances remained the same in the second time.

Table 3. Participants who performed physical capabilities as expected, according to the stablished cutoff scores.

\begin{tabular}{lcccc}
\hline & \multicolumn{2}{c}{ Intervention $(\mathrm{n}=35)$} & \multicolumn{2}{c}{ Control $(\mathrm{n}=36)$} \\
\hline Characteristics & Pre & Post & Pre & Post \\
\hline Handgrip stength (KgF) & $\mathrm{n}(\%)$ & $\mathrm{n}(\%)$ & $\mathrm{n}(\%)$ & $\mathrm{n}(\%)$ \\
\hline 5XSST (s) & $20(57.4)$ & $29(82.9)$ & $35(97.2)$ & $35(97.2)$ \\
30-s CST (times) & $10(28.6)$ & $20(55.6)$ & $7(19.4)$ \\
Right one-leg stance test (s) & $34(97.1)$ & $35(100)$ & $34(94.4)$ & $35(97.2)$ \\
Left one-leg stance test (s) & $34(97.1)$ & $35(100)$ & $34(94.4)$ & $35(97.2)$ \\
TUG test (s) & $34(97.1)$ & $35(100)$ & $36(100)$ & $36(100)$ \\
6MWT (m) & $7(25)$ & $4(14.3)$ & $5(20)$ & $2(8)$ \\
\hline
\end{tabular}

TUG = Timed Up and go, $\mathrm{s}=$ seconds, $\mathrm{KgF}=$ kilogram-force, $5 \mathrm{XSST}=5$ times sit-to-stand, 30-s CST=30-second chair stand test, 6MWT=6-minute walk test, $\mathrm{n}(\%)=$ number of older adults who performed the test above the stablished cutoff score (percentage).

\section{DISCUSSION}

The study aimed to assess the effects of the addition of a dual task to multicomponent training in physical performances of older adults who practice physical exercise. The CG presented greater flexibility than the IG, regardless of time. Furthermore, after 12-week intervention, there was a worsening in the 5XSST and in the 30-s CST, regardless of group. Only the IG presented an impairment in TUG performance between times. However, when analysing the results based on cut-off scores, both groups maintained physical performances.

The mean BMI of the sample was $27.9 \mathrm{~kg} / \mathrm{m}^{2}$, considered as pre-obesity by the World Health Organization (2000) ${ }^{22}$. Based on the cut-off score of 3.19 points for the $\mathrm{MBQE}^{23}$, the sample was composed of non-sedentary older adults. Among Brazilian older adults, about $30 \%$ are fallers ${ }^{24}$. In contrast, in the present study, only $5.6 \%$ of the participants were fallers, probably due to the protective factor of practicing physical exercise. According to a meta-analysis study, both physical exercises interventions applied alone and combinations of interventions were associated with a low risk for falls ${ }^{25}$.

The CG presented a greater flexibility score than the IG regardless of time. A study evaluated the effects of multicomponent training (3 times per week) for 9 weeks in healthy and independent older adults ${ }^{26}$. Their 
findings are similar to the present study, since the authors did not identify significant effects on flexibility, measured by the Wells bench. Although this instrument is commonly used in clinical practice, there was a high degree of dispersion between values found in both groups. Thus, other methods could be included to promote an accurate flexibility assessment. Furthermore, Toraman et al. ${ }^{26}$ justified the absence of a significant increase in flexibility due to the short period of training. Although our training protocol adopted recommendations for older adults ${ }^{2}$, it is possible that 12 weeks of intervention and the volume of training were insufficient to provide a significant result for flexibility of older adults who already performed regular and systematic physical exercise.

Regarding lower limb muscular strength, Li et al. ${ }^{27}$ assessed a group of healthy older adults submitted to a dual task training (1 hour, 5 sessions of dual task), compared to an untrained control group. There were no significant improvements in lower limb strength (30-s CST) after the dual task training. The volunteers have already had a high level of physical activity and achieved the maximum capacity of the test. In the present study, there was a worse performance in lower limb strength in both groups, assessed by the 5 XSST and the 30-s CST, even with a longer period of training compared to the study of $\mathrm{Li}$ et al. ${ }^{27}$. Thus, more strength and resistance exercises for lower limbs should be emphasized in the multicomponent training, since they are essential for daily living activities in older adults.

Carvalho et al. ${ }^{28}$ found a significant improvement after a multicomponent training (2 times per week) for 32 weeks. However, different from our study, these authors selected older adults who had not performed moderate/ vigorous physical exercises for two years prior to the training protocol. It is suggested that the lack of improvement in muscle strength in this study may be due to a physiological adaptation, which could restrict additional benefit of muscle strength in older individuals who have practiced physical exercise regularly for a long time.

In the present study, the IG presented worse mobility performance, assessed by the TUG test, and no changes in static balance tests were found over time. However, regarding to the recommended cut-off score for risk of falling ${ }^{19}$, most of the participants of both groups have already presented good performance in TUG and balance tests at baseline and after training. In addition, as a result of aging, there is an impairment ability of dividing attention in dual task activities ${ }^{10}$. Thus, when competing attention between tasks, it is possible that the IG prioritized the new stimulus (cognitive task) instead of physical exercise.

Regarding aerobic capacity, there was no change in the performance of either group. In accordance, other studies ${ }^{28,29}$ did not find significant effects in aerobic capacity, assessed by the 6MWT and 2-minute step test, after multicomponent training. Furthermore, Fraser et al. ${ }^{30}$ also found no changes in the 6MWT among groups who trained physical (aerobic and stretch) with cognitive components (cognitive tasks and computer lessons). These results suggest that, although the multicomponent training agrees with 
recommendations for older adults ${ }^{2}$, the low duration of aerobic component could be insufficient to achieve the expected improvement for both groups.

The results of this study were restricted because the sample was composed only of older adults who practice physical exercise, which could justify the absence of improvements in physical performance. Moreover, it is possible that findings would be different if the authors had adopted an intervention period greater than 12 weeks. Additionally, it is important to consider that new studies should be conducted in this population, including specific cutoff scores of common physical performance tools.

The limitations of the present study included non-randomization of groups, non-blinding of evaluators, non-use of an instrument that measures the level of physical activity as an inclusion criteria and the use of cutoff scores of the tools for general older people (not specific for Brazilian older people who practice physical exercise due to a lack of information in the literature). In addition, the use of the one-leg stance test may be considered as a limitation of this study, because many older adults who practice physical activity reach the maximum score. Nevertheless, the study was innovative in demonstrating motor effects of the addition of dual task to multicomponent training in older adults who practice physical exercise.

\section{CONCLUSIONS}

In conclusion, the addition of a dual task to the multicomponent training was not able to improve physical performances of older adults. Despite positive effects on cognitive performance with dual task in different populations, further studies are needed to confirm whether this type of intervention contributes to cognitive benefits associated with the maintenance of physical abilities in community-dwelling older adults who practice physical exercise.

\section{Acknowledgement}

We thank the FESC (Fundação Educacional São Carlos) for ceding the infrastructure for the Revitalization Geriatric Program.

\section{REFERENCES}

1. KrallJR, Carlson MC, Fried LP, Xue QL. Examining the dynamic, bidirectional associations between cognitive and physical functioning in older adults. Am J Epidemiol 2014;180(8):838-846.

2. American College of Sports Medicine, Chodzko-Zajko WJ, Proctor DN, Singh MA, Minson CT, Nigg CR, et al. American College of Sports Medicine position stand. Exercise and physical activity for older adults. Med Sci Sports Exerc 2009;41(7):1510-1530.

3. Nishiguchi S, Yamada M, Tanigawa T, Sekiyama K, Kawagoe T, Suzuki M, et al. A 12-week physical and cognitive exercise program can improve cognitive function and neural efficiency in community-dwelling older adults: a randomized controlled trial. J Am Geriatr Soc 2015;63(7):1355-1363.

4. Ahlskog JE, Geda YE, Graff-Radford NR, Petersen RC. Physical Exercise as a preventive or disease-modifying treatment of dementia and brain aging. Mayo Clin Proc 2011;86(9):876-884. 
5. Law LLF, Barnett F, Yau MK, Gray MA. Effects of combined cognitive and exercise interventions on cognition in older adults with and without cognitive impairment: a systematic review. Ageing Res Rev 2014;15:61-75.

6. de Andrade LP, Gobbi LTB, Coelho FGM, Christofoletti G, Riani Costa JL, Stella F. Benefits of multimodal exercise intervention for postural control and frontal cognitive functions in individuals with Alzheimer's disease: a controlled trial. J Am Geriatr Soc 2013;61(11):1919-1926.

7. Fok P, Farrell M, McMeeken J. The effect of dividing attention between walking and auxiliary tasks in people with Parkinson's disease. Hum Mov Sci 2012;31(1):236-246.

8. Yokoyama H, Okazaki K, Imai D, Yamashina Y, Takeda R, Naghavi N, et al. The effect of cognitive-motor dual-task training on cognitive function and plasma amyloid $\beta$ peptide $42 / 40$ ratio in healthy elderly persons: a randomized controlled trial. BMC Geriatr 2015;15:60.

9. Falbo S, Condello G, Capranica L, Forte R, Pesce C. Effects of physical-cognitive dual task training on executive function and gait performance in older adults: a randomized controlled trial. Biomed Res Int 2016;2016:5812092.

10. Reve EV, de Bruin ED. Strength-balance supplemented with computerized cognitive training to improve dual task gait and divided attention in older adults: a multicenter randomized-controlled trial. BMC Geriatr 2014;14:134.

11. Kwon S, Perera S, Pahor M, Katula JA, King AC, Groessl EJ, et al. What is a meaningful change in physical performance? Findings from a clinical trial in older adults (the LIFE-P study). J Nutr Health Aging 2009;13(6):538-544.

12. Mazo G, Liposcki D, Ananda C, Prevê D. Health conditions, incidence of falls and physical activity levels among the elderly. Rev Bras Fisioter 2007;11(6):437-442.

13. Voorrips LE, Ravelli AC, Dongelmans PC, Deurenberg P, Van Staveren WA. A physical activity questionnaire for the elderly. Med Sci Sports Exerc 1991;23(8):974-979.

14. Chiu AY, Au-Yeung SS, Lo SK. A comparison of four functional tests in discriminating fallers from non-fallers in older people. Disabil Rehabil 2003;25(1):45-50.

15. Wells KF, Dillon EK. The sit and reach-a test of back and leg flexibility. Res Quarterly Am Assoc Heal Phys Educ Recreat 1952;23(1):115-118.

16. Vasconcelos KS, Dias JM, Bastone AC, Vieira RA, Andrade AC, Perracini $\mathrm{MR}$, et al. Handgrip strength cutoff points to identify mobility limitation in community-dwelling older people and associated factors. J Nutr Health Aging 2016;20(3):306-315.

17. Rikli R, Jones C. Functional fitness normative scores for community residing older adults, ages 60-94. J Aging Phys Act 1999;7(2):162-81.

18. Freire AN, Guerra RO, Alvarado B, Guralnik JM, Zunzunegui MV. Validity and reliability of the Short Physical Performance Battery in two diverse older adult populations in Quebec and Brazil. J Aging Health 2012;24(5):863-78.

19. Alexandre TS, Meira DM, Rico NC, Mizuta SK. Accuracy of Timed Up and Go Test for screening risk of falls among community-dwelling elderly. Rev Bras Fisioter 2012;16(5):381-388.

20. Vellas BJ, Wayne SJ, Romero L, Baumgartner RN, Rubenstein LZ, Garry PJ. One-leg balance is an important predictor of injurious falls in older persons. J Am Geriatr Soc 1997;45(6):735-738.

21. Ansai JH, de Andrade LP, Buto MS, Barroso VV, Farche AC, Rossi PG, et al. Effects of the Addition of a Dual Task to a Supervised Physical Exercise Program on Older Adults' Cognitive Performance. J Aging Phys Act 2017;25(2):234-239.

22. World Health Organization. Obesity: Preventing and Managing the Global Epidemic: Report of a WHO Consultation. Geneva; 2000.

23. Silva VM, Gonçalves CT, Silva JJ, Gobbi LTB. Mobilidade de idosos em ambiente doméstico: efeitos de um programa de treinamento específico. Rev Bras Ativ Fis Saúde 2003;8(1):5-19.

24. Perracini MR, Ramos LR. Fall-related factors in a cohort of elderly community residents. Rev Saude Publica 2002;36(6):709-716. 
25. Tricco AC, Thomas SM, Veroniki AA, Hamid JS, Cogo E, Strifler L, et al. Comparisons of Interventions for preventing falls in older adults: a systematic review and meta-analysis. JAMA 2017;318(17):1687-1699.

26. Toraman NF, Erman A, Agyar E. Effects of multicomponent training on functional fitness in older adults. J Aging Phys Act 2004;12(4):538-553.

27. Li KZH, Roudaia E, Lussier M, Bherer L, Leroux A, McKinley PA. Benefits of cognitive dual-task training on balance performance in healthy older adults. Journals Gerontol Ser A Biol Sci Med Sci 2010;65A(12):1344-1352.

28. Carvalho MJ, Marques E, Mota J. Training and detraining effects on functional fitness after a multicomponent training in older women. Gerontology 2009;55(1):41-48.

29. Kang S, Hwang S, Klein AB, Kim SH. Multicomponent exercise for physical fitness of community-dwelling elderly women. J Phys Ther Sci 2015;27(3):911-915.

30. Fraser SA, Li KZ-H, Berryman N, Desjardins-Crépeau L, Lussier M, Vadaga K, et al. Does combined physical and cognitive training improve dual-task balance and gait outcomes in sedentary older adults? Front Hum Neurosci 2017;10:688.

\section{CORRESPONDING AUTHOR}

Juliana Hotta Ansai

UFMS -Federal University of Mato

Grosso do Sul, Department of

Physical Therapy Campo Grande, MS, Brazil

Costa e Silva Avenue, without

number

Universitário Neighborhood

Zip Code: $79070-900$

E-mail: juliana.h.ansai@ufms.br 